\title{
(Co)variances for reproduction, egg weight and chick weight in ostriches
}

\author{
S.W.P. Cloete ${ }^{1 \#}$, K.L. Bunter ${ }^{2}$, Z. Brand ${ }^{3}$ and H. Lambrechts ${ }^{3}$ \\ ${ }^{1}$ Elsenburg Agricultural Centre, Private Bag X1, Elsenburg 7607, South Africa \\ ${ }^{2}$ Animal Genetics and Breeding Unit, University of New England, Armidale 5900, NSW, Australia \\ ${ }^{3}$ Klein Karoo Agricultural Development Centre, P.O. Box X529, Oudtshoorn 5900, South Africa
}

\begin{abstract}
The study investigated genetic parameters for egg and chick production recorded over an 8-month breeding season, as well as average egg and chick weight for pair-bred ostrich females. Estimates of $\mathrm{h}^{2}$ were moderate for reproduction traits and very high for average egg and chick weight, where all traits were expressed as a trait of the dam. Genetic and phenotypic correlations were positive in sign for all trait combinations. Selection for an increased reproduction rate would thus not lead to an unwanted (downwards) correlated response in average egg or chick weight. Averaged annual breeding values for egg and chick production in breeding females increased at 1.4 and $2.3 \%$ per year, respectively. These results indicate that the genetic improvement of ostriches is feasible, provided that obstacles hampering it are overcome.
\end{abstract}

Keywords: Breeding values, chick production, egg production, heritability, genetic correlations ${ }^{\#}$ Corresponding author. E-mail: schalkc@elsenburg.com

\section{Introduction}

Genetic gains in the major farm livestock species have been commonly reported over the last decade. The ostrich industry is in stark contrast to these examples, and little has been achieved as far as genetic progress is concerned. Challenges facing scientists that are interested in the genetic improvement of ostriches are listed in the literature (Cloete et al., 1998; 2002a; Bunter, 2002). In domestic poultry species, it is accepted that reproduction is negatively related to egg weight (Gowe \& Fairfull, 1995). Information is scant on such correlations in ostriches. Indications are that it may not conform to the corresponding correlations in poultry (Bunter, 2002). (Co)variance estimates for reproduction, as well as average egg and chick weight were studied for an ostrich population. Genetic trends for reproduction were also derived.

\section{Material and Methods}

The experimental population was a commercial, pair-bred ostrich flock at the Klein Karoo Agricultural Development Centre near Oudtshoorn. The experimental site, as well as the management and husbandry of the flock, are described in the literature (Cloete et al., 1998; Bunter, 2002). Ostrich breeding pairs were mated for a joining season of approximately 8 months over the period $1991-2001$. Individual egg and chick production records were determined as described by Bunter (2002). Weights of individual eggs and day-old chicks were recorded and averaged for dams within annual production seasons. Only averages based on $>4$ eggs were considered. The flock was subjected to a measure of phenotypic selection for reproduction rate, whereby male and female progeny of pairs with a good reproduction rate were the preferred replacements. All data were initially subjected to single trait analyses, using ASREML (Gilmour et al., 1999). Fixed effects included in the analyses were age of female and production year. The following random models were considered (in matrix notation):

$$
\begin{aligned}
& \mathrm{y}=\mathrm{Xb}+\mathrm{Z}_{1} \mathrm{a}+\mathrm{e} \\
& \mathrm{y}=\mathrm{Xb}+\mathrm{Z}_{2} \mathrm{C}_{\text {female }}+\mathrm{e} \\
& \mathrm{y}=\mathrm{Xb}+\mathrm{Z}_{1} \mathrm{a}+\mathrm{Z}_{2} \mathrm{C}_{\text {female }}+\mathrm{e} \\
& \mathrm{y}=\mathrm{Xb}+\mathrm{Z}_{1} \mathrm{a}+\mathrm{Z}_{2} \mathrm{C}_{\text {female }}+\mathrm{Z}_{3} \mathrm{C}_{\text {service sire }}+\mathrm{e}
\end{aligned}
$$

where $y$ is a vector of observations; $b, a, c_{\text {female }}$ and $c_{\text {service sire }}$ are vectors of fixed effects, additive genetic effects and permanent environmental effects of hens or their mates; $X, Z_{1}, Z_{2}$, and $Z_{3}$ are the corresponding incidence matrices relating the records to effects; and e is the vector of residuals

It was assumed that:

$$
\mathrm{V}(\mathrm{a})=\mathrm{A} \sigma_{\mathrm{a}}^{2} ; \mathrm{V}\left(\mathrm{c}_{\text {female }}\right)=\mathrm{I} \sigma_{\text {female }}^{2} \mathrm{~V}\left(\mathrm{c}_{\text {service sire }}\right)=\mathrm{I} \sigma_{\text {service sire }}^{2} \text { and } \mathrm{V}(\mathrm{e})=\mathrm{I} \sigma_{\mathrm{e}}^{2} \text {, }
$$

where $\mathrm{A}$ is a matrix describing relationships between animals (i.e., the numerator relationship matrix), $\mathrm{I}$ is an identity matrix; and $\sigma_{\mathrm{a}}^{2}, \sigma_{\text {female, }}^{2} \sigma_{\text {service sire }}^{2}$ and $\sigma_{\mathrm{e}}^{2}$ are the variation attributable to additive genetic effects, permanent environmental effects of the hen, and/or her mate, and environmental (residual) effects respectively. Random terms were added to analytical models sequentially. Log-Likelihood Ratios were used 
to assess the significance of the contribution of each random term to improvements in the model for analysis. The test is based on testing twice the improvement in the Log-Likelihood resulting from adding a random term to the model as a $\mathrm{Chi}^{2}$ statistic, at one degree of freedom. For two models with the same number of random terms, and assuming identical fixed effects, the model with the higher value for the Log-Likelihood fits the data better. Variance components were expressed relative to the overall phenotypic variance for each trait to derive estimates of the appropriate variance ratios. All analyses included the full pedigree file, consisting of 601 individuals, the progeny of 135 males and 132 females. With the data set used, approximately two generations were involved on average. These analyses were followed by two-trait analyses involving correlations between random factors appropriate to the specific combination of the traits. Predicted breeding values for reproduction were obtained for individual animals from univariate analyses, averaged within hatching years and regressed on year of hatch, to indicate genetic progress in the flock. No genetic trends were evident for average weights, and these results were excluded.

\section{Results and Discussion}

Egg weight and day-old chick weight had coefficients of variation below 15\%, while egg and chick production were more variable (Table 1). These results conformed to previous results from the same population, but based on smaller data sets (Van Schalkwyk et al., 1996; Cloete et al., 1998; Bunter, 2002).

Heritability $\left(\mathrm{h}^{2}\right)$ estimates were in the medium range for reproduction traits, and very high for the egg traits (Table 2). The study confirms moderate $h^{2}$ estimates for reproduction in ostriches, leading to recommendations that the available variation could be exploited in well-structured breeding programs, benefiting subsequent generations as well as the current flock (Bunter et al., 2001a; Bunter, 2002; Cloete et al., 2002a; 2002b). Selection progress in egg and chick traits of dams also seems likely, if desired. Estimates for average egg and chick weights were previously partitioned in genetic and permanent environmental components (Bunter, 2002). Female permanent environment affected egg production and chick production, ratios ranging from 0.16 to 0.18 , as reported by Cloete et al. (2002b). Service sire affected chick production, egg weight and chick weight, but the estimated variance ratios failed to exceed 0.10 .

Table 1 Descriptive statistics for the traits analysed for breeding ostrich females

\begin{tabular}{lccc}
\hline Trait & Observations (n) & Mean \pm s.d. & Range \\
\hline Egg production/dam/season (n) & 1177 & $46.3 \pm 24.5$ & $0-121$ \\
Chick production /dam/season (n) & 1177 & $22.9 \pm 19.0$ & $0-90$ \\
Average egg weight /dam (g) & 1062 & $1419 \pm 123$ & $825-1827$ \\
Average chick weight/dam (g) & 957 & $858 \pm 85$ & $607-1137$ \\
\hline
\end{tabular}

Table 2 (Co)variance ratios ( \pm s.e.) for production traits assessed in ostrich breeding females. Estimates of heritability (upper), female permanent environment (middle) and service sire permanent environment (lower) are given in bold on the diagonal. Genetic (upper), permanent environmental (middle) and service sire correlations (lower) are given above the diagonal. Residual (upper) and phenotypic correlations (middle) are given below the diagonal.

\begin{tabular}{lcccc}
\hline Trait & \multicolumn{3}{c}{ Trait } \\
\cline { 2 - 5 } & Egg production & Chick production & Egg weight & Chick weight \\
\hline Egg production/dam/season (n) & $\mathbf{0 . 2 6} \pm \mathbf{0 . 0 9}$ & $1.11 \pm 0.08$ & $0.26 \pm 0.11$ & $0.00 \pm 0.12$ \\
& $\mathbf{0 . 1 6} \pm \mathbf{0 . 0 8}$ & $0.70 \pm 0.13$ & - & - \\
& - & - & - & - \\
\hline Chick production/dam/season (n) & $0.73 \pm 0.02$ & $\mathbf{0 . 2 1} \pm \mathbf{0 . 0 8}$ & $0.27 \pm 0.13$ & $0.14 \pm 0.12$ \\
& $0.78 \pm 0.02$ & $\mathbf{0 . 1 8} \pm \mathbf{0 . 0 8}$ & - & - \\
& - & $\mathbf{0 . 0 9} \pm \mathbf{0 . 0 4}$ & $0.10 \pm 0.25$ & $0.32 \pm 0.26$ \\
\hline Average Egg weight/dam (g) & $0.42 \pm 0.03$ & $0.30 \pm 0.04$ & $\mathbf{0 . 7 2} \pm \mathbf{0 . 0 4}$ & $0.88 \pm 0.03$ \\
& $0.26 \pm 0.05$ & $0.21 \pm 0.05$ & - & - \\
\hline Average Chick weight/dam (g) & - & - & $\mathbf{0 . 0 8} \pm \mathbf{0 . 0 3}$ & $0.99 \pm 0.05$ \\
\hline & $0.21 \pm 0.04$ & $0.24 \pm 0.04$ & $0.75 \pm 0.02$ & $\mathbf{0 . 7 4} \pm \mathbf{0 . 0 3}$ \\
& - & $0.14 \pm 0.05$ & $0.88 \pm 0.01$ & - \\
& & - & - & $\mathbf{0 . 0 7} \pm \mathbf{0 . 0 3}$ \\
\hline
\end{tabular}

- $\quad$ Effect not estimated 
Reproduction traits were generally positively related to egg and chick weight on a genetic level (Table 2), although only the correlations involving egg weight were significant. These results accords with earlier research by Bunter et al. (2001b) and Bunter (2002) that reproduction and early progeny weight are not unfavourably correlated on the individual female level. It does, however, not agree with the general consensus in chickens, where higher levels of reproduction are generally accompanied by lower egg weights (Gowe \& Fairful, 1995). Bunter (2002) hypothesized that this difference in the direction of the genetic correlation was probably caused by the fact that poultry achieve production levels much closer to their potential than ostriches. Phenotypic and environmental correlations between traits were generally positive and very high between egg and chick production, and also between egg and chick weight.

Genetic trends ( $\mathrm{b} \pm$ s.e.) derived from predicted breeding values, were $0.67 \pm 0.05$ for egg production $\left(\mathrm{R}^{2}=0.80\right)$ and $0.52 \pm 0.04$ for chick production $\left(\mathrm{R}^{2}=0.78\right)$ per year. Expressed relative to average performance in the flock, these trends amounted to 1.4 and 2.3\% per year respectively and were positive and significant $(\mathrm{P}<0.01)$. No other study reporting genetic trends for ostriches were found, but the rate of progress attained was comparable with that achieved in other species.

\section{Conclusions}

Egg and chick weight were not unfavorably related to reproduction in ostriches, thus simplifying decisions with regard to a practical selection index based on economic principles. The production of chicks is the primary objective in ostrich breeding. Low live weight chicks at day-old were more likely to succumb in the month following artificial hatching than their heavier contemporaries (Cloete et al., 2001). An unfavorable genetic correlation of reproduction traits with egg and/or chick weight thus would have the potential to eventually impair the viability of chicks in commercial operations.

Reproduction traits were shown to respond to phenotypic selection, setting the scene for extrapolating the present results to other ostrich populations. The scope for genetic selection using derived breeding values in the ostrich industry appears good, provided that a feasible and affordable recording and evaluation scheme can be devised. Obstacles regarding breeding structure and recording difficulties, however, need to be overcome to make this possible (Cloete et al., 2002a).

\section{References}

Bunter, K.L., 2002. The Genetic Analysis of Reproduction and Production Traits Recorded for Farmed Ostriches (Struthio camelus). Ph.D. dissertation, University of New England, Armidale, Australia.

Bunter, K.L., Cloete, S.W.P., Van Schalkwyk, S.J. \& Graser, H.-U., 2001a. Factors affecting reproduction in farmed ostriches. Proc. Assoc. Advmnt Anim. Breed. Genet. 14, 43-46.

Bunter, K.L., Cloete, S.W.P., Van Schalkwyk, S.J. \& Graser, H.U., 2001b. Relationships between measures of reproductive performance in farmed ostrich hens. Proc. Assoc. Advmnt Anim. Breed. Genet. 14, 47-50.

Cloete, S.W.P., Bunter, K.L. \& Van Schalkwyk, S.J., 2002a. Progress towards a scientific breeding strategy for ostriches. Proc. $7^{\text {th }}$ World Cong. Genet. Appl. Livest. Prod. 30, 561-568. 18-23 August, Montpellier, France.

Cloete, S.W.P., Bunter, K.L., Van Schalkwyk, S.J. \& Brand, Z., 2002b. Genetic parameters for live weight and reproduction in ostrich females. Proc. $1^{\text {st }}$ Joint Cong. Grassl. Soc. Sthn. Afr. \& S. Afr. Soc. Anim. Sci., 13-16 May 2002, Christiana Aventura, 81.

Cloete, S.W.P., Lambrechts, H., Punt, K. \& Brand, Z., 2001. Factors related to high levels of ostrich chick mortality to 90 days after hatching in an intensive rearing system. J. S. Afr. Vet. Assoc. 72, 197-202.

Cloete, S.W.P., Van Schalkwyk, S.J. \& Brand, Z., 1998. Ostrich breeding - progress towards a scientifically based strategy. Proc. $2^{\text {nd }}$ Int. Ratite Cong., 21-25 September 1998, Oudtshoorn. pp 55-62.

Gilmour, A.R., Cullis, B.R., Welham, S.J. \& Thompson, R., 1999. ASREML - Reference manual. NSW Agriculture Biometric Bulletin No. 3. NSW Agriculture, Orange Agricultural Institute, Forest Road, Orange 2800, NSW, Australia.

Gowe, R.S. \& Fairfull, R.W., 1995. Breeding and genetics of egg laying chickens. In: Poultry Production. Ed: Hunton, P., World Animal Science: Volume 9, Sub-series C: Production System Approach, Elsevier, The Netherlands. pp. 435-456.

Van Schalkwyk, S.J., Cloete, S.W.P. \& De Kock, J.A., 1996. Repeatability and phenotypic correlations for live weight and reproduction in commercial ostrich breeding pairs. Br. Poult. Sci. 37, 953-962. 